\title{
Some Dangers in Parole Prediction
}

\author{
Ralph W. England, Jr. \\ Chairman, Department of Sociology, University of Rhode Island \\ Assistant Professor of Sociology, University of Illinois, 1955-60; \\ Instructor in Sociology, University of Pennsylvania, 1947-55 \\ B.A., 1941, University of Michigan; M.A., 1947, Ph.D., 1954, University of Pennsylvania
}

As prediction techniques are perfected and increasingly used, certain incongruities existing between parole theory and parole prediction may have detrimental effects on parole itself. The inadequacies of substandard parole jurisdictions may become less evident if only good risks are released; challenge to professional skills may be reduced; the administrative advantages inherent in prediction may supersede correctional ends; the principle of individualized treatment may be threatened. The best use to which prediction can be put is in the identification of prisoners whose parole tends to bring this measure into public disrepute.

7 HE intellectual challenge and excitement of parole prediction research has drawn to it some of the best minds in American and European academic criminology. In a discipline long frustrated in its causation research by the knotty problems of definition, sampling, concept construction, and research design, prediction work stands as a fertile and tempting islet upon whose soil the statistically oriented social scientists are bringing to fruition projects close to the dual aims of all scientific endeavor: prediction and control. The continued development and refinement of parole prediction devices and an increase in their practical application seem extremely likely to me. The various problems yet to be solved-unreliability of prison records, the need to precisely measure attitude and character traits, the present inability to correct for disparity between the social milieus of the experience table parolees and the future milieus of the predicted parolees, to name a few ${ }^{1}$-are largely technical. Their solution within the next ten years or so seems possible in view of the rapid advances being made in statistics, computer technology, social research methods, and the behavioral sciences.

My reservations about the use of parole prediction devices are not based, therefore, upon their present transitional shortcomings, but upon what I regard as the very nature of their application, which is inimical to sound correctional theory and practice.

\section{Inadequate Parole Perpetuated}

Parole theory emphasizes that adequate parole entails positive, constructive efforts by trained and experienced persons who work, within

${ }^{1}$ Paul W. Tappan, Crime, Justice and Correction (New York: McGraw Hill, 1960), pp. 731-733. 
a favorable procedural and community setting, in the behalf of exprisoners. In practice, of course, few state parole systems can boast of meeting "ideal" standards: caseloads are too heavy; many officers do not meet professional qualifications; community facilities lack adequate referral services; politics intrude. Progress in meeting good standards of parole can be seriously impeded if the practice becomes widespread of paroling only those prisoners who can "survive" what are, in general, substandard parole conditions. The shortcomings of a poorly trained physician can be ignored if he has only healthy patients. The use of high-quality prediction devices within low-quality parole jurisdictions will make possible the accurate selection of lowrisk cases for parole, thus virtually guaranteeing that these areas will eventually boast high success rates. This may already be afoot in Illinois, a state which has pioneered in the routine use of prediction devices but which is not known for its outstanding parole system. Reported parole violation rates declined from 57 per cent in 1926 to 26 per cent in 1943, with a shift from a preponderance of major to a preponderance of minor violations. At the same time, however, the proportion of Illinois prisoners released on parole decliner from 69.3 per cent in $1926^{2}$ to as low as 38 per cent in 1952; by 1960 it had climbed to 51.9 per cent but was still considerably lower than the proportion of prisoners paroled in four neighboring states. ${ }^{3}$

\footnotetext{
Ibid., p. 734.

- National Prisoner Statistics, U.S. Department of Justice, Aug., 1953, Table 3, and Sept., 1961, Table 3.
}

Common sense would lead one to believe that the quality of parole that a released man experiences would have some causal connection with success or failure, and that prediction devices should take cognizance of this connection by including factor categories pertaining to parole quality. ${ }^{4}$ However, the methodology of prediction prohibits such inclusion because prisoners who have had no previous parole experience cannot be scored in these categories. Consequently, prediction devices must operate not only as though parole quality were uniform for every parolee released within a particular jurisdiction but also as though the quality were sufficient to assure success, providing the prisoner's prior characteristics do not predispose him otherwise. Given the present structuring of prediction devices, failure on parole cannot be attributed to inadequacies in the parole process. Thus, parole as a corrective measure is insulated from being spotlighted as a variable in success or failure.

\section{Prediction and Professional Challenge}

Fundamental to the morale of the trained and qualified parole agent is the challenge of working with parolees who, without his assistance, stand a good change of becoming

'The Illinois prediction table described in Lloyd Ohlin's Selection for Parole (New York: Russell Sage Foundation, 1951) is the only prediction device $I$ know of that uses a factor at all related to parole qualityparole job prospect-and it does so only indirectly. Glaser's effort to find better prediction factors using Illinois data resulted in the elimination of this item from his table. (See Daniel Glaser, "A Reconsideration of Some Parole Prediction Factors," American Sociological Review, June, 1954, p. 340.) 
recidivists. Professionals worthy of the label-whether in law, medicine, theology, accountancy, engineering, or correction-thrive on problems requiring practical application of the theoretical underpinnings of their callings. Purely routine matters can be relegated to technicians; professionals deal with complex and problematical situations whose solutions require the exercise of talents far transcending those needed for technical operations. To "take the risk out of parole" by releasing only those estimated to be good bets would reduce parole to a merely technical level for which the limited talents of office clerks and policemen-turnedparole-agents would suffice.

My hunch is that most low-risk prisoners, as determined by prediction devices, are those who, so far as their recidivist tendencies are concerned, should not have been imprisoned at all. That they are imprisoned testifies to the continuing archaic demand by legal authorities and the public for punishment and example-setting rather than to the judges' perception that these convicted persons need rehabilitation in prison. If this hunch is correct, parole agents whose clients are picked for them by prediction tables are serving as unwitting handmaidens to punitive rather than correctional ends. Nothing in parole theory countenances this decidedly nonprofessional function. Quite the opposite. High-risk prisoners with decided criminal leanings are those most desperately in need of whatever truly rehabilitative resources a state can provide, including professional parole. Ironically, prediction devices encourage parole releases at the wrong end of the risk spectrum.

\section{An Administrative Aid Only}

The indigenous conservatism of administrative bodies, with their desire for smooth, uneventful operations and their avoidance of the problematical and risky, will, I fear, lead an increasingly perfected parole prediction technique to function wholly as an administrative rather than as a correctional instrument-to the ultimate detriment of parole. One solid virtue of the present "clinical guess" system now in use (whose predictive power is, for the time being, not very different from today's relatively crude prediction tables) is that it embodies an uncertain degree of risk-an uncertainty which may be promoting greater use of parole today than we can ultimately expect.

Not all parole boards are charged with direct responsibility for field operations; their members are not, strictly speaking, administrators, but they share with the administration the fact that their release decisions are open to public scrutiny and judgment. While routine decisions made by other state officials are obscured by the complexities of government operations, those of parole boards can at any time be brought sensationally to public attention, especially their "wrong" decisions in releasing men who later commit heinous crimes. Although the furor created by such cases sometimes results in unfair criticism of parole boards, the criticism is keenly felt in several echelons of government and can have serious political repercussions.

Both in prison and on parole an offender is presumably undergoing treatment. Parole theory does not define parole as a "testing" of the offender's capacity for conventional 
behavior but rather as a continuation of corrective measures begun during incarceration. But parole prediction does not in any sense predict progress through a correctional program; rather, it gives the odds that an untoward incident (usually a technical violation or a new offense) will or will not occur. Moreover, parole prediction operates on the assumption that parole is a testing period, and it implements this erroneous assumption by selecting for release those prisoners least likely to fail the test. Why isn't equal encouragement given to predicting untoward incidents during imprisonment-which, after all, is simply a preceding stage in the correctional process? The answer is, I think, that disapproved behavior in prison has few public repercussions; even if this were not so, the public would be hard put to identify the responsible prison officials and accuse them of bad judgment. Parole prediction's greatest value is its power to maximize administrative tranquility and to minimize embarrassment to paroling officials. Placing such a tool in their hands would, it seems to me, initiate a chain of events leading in an entirely opposite direction from the one specified by parole theory.

\section{Prediction vs. Individualization}

The American Correctional Association has defined parole as "a procedure by which prisoners are selected for release on the basis of individual response and progress within the correctional institution and a service by which they are provided with necessary controls and guidance as they serve the remainder of their sentences within the free community." Clearly

- Manual of Correctional Standards (New York: American Correctional Association, 1959), p. 532 (emphasis added). reflected here are the ideas that imprisonment and parole are continuous parts of a corrective process and that a prisoner cannot reasonably pass from one to the next until sufficient progress within the first stage has been made. While the supporters of prediction could claim that measurements of institutional progress are indirectly incorporated into prediction devices (since the "good" and "bad" parole risks are prisoners whose progress has been, respectively, sufficient and insufficient), this exceedingly awkward and remote measure is wholly adventitious. Moreover, the development of good prediction tables does not necessarily entail the development of measures of progress through an institutional program because such measures are not directly relevant to the prediction researcher's hunt for reliable, valid, and efficient predictors. Most predictive factors in studies made during the last twenty years have been drawn from the preincarceration period of the subjects' lives: work history, previous convictions, character type. The few factors that have been derived from prison experiences were selected solely because they proved to be good predictors. ${ }^{6}$

Parole decisions made by exclusive use of prediction devices (an inherent tendency as their perfection nears) would not require assessments of "individual response and progress within the correctional institution." This

- Ohlin's table, upon which Illinois parolc partly depended, contained no in-prison factors; Glaser's Illinois revision included use of prison time (Glaser, op. cit., p. 340). Among Mannheim's and Wilkins' eleven factors are three concerning Borstal conduct: absconds, misdemeanors, and transfer to an open Borstal; see Hermann Mannheim and Leslie T. Wilkins, Prediction Methods in Relation to Borstal Training (London: H. M. Stationery Office, 1955), pp. 145, 155. 
difficult and exacting task is neatly sidestepped and an important canon of individual treatment violated.

Ideally, every prisoner released from a correctional institution should go out under supervision; the practice of holding some offenders to the expiration of their terms until "their debt is paid" is an exercise in futility. Practically, however, this policy would be difficult to implement in most jurisdictions, public sentiment being what it is. Sooner or later some paroles prove so extraordinarily unpopular that impractical idealism might only jeopardize the needed liberalization of parole. But what are these unpopular paroles? What offenses are involved? What kinds of individuals? Under what circumstances does their unpopularity become manifest? The greatest service prediction researchers could perform for parole would be to construct tables identifying those prisoners whose parole tends to bring this measure into disrepute.

\section{Conclusions}

The general business of handling behavioral deviants-including those we label criminal-is still largely unscientific. Correction especially is an unsettled amalgam of ideas and practices accumulated over the last several centuries. Stone walls and iron bars enclose fluorescent lights and psychologists' pastel quarters; prisoners sentenced under the stern aegis of public moral condemnation are subjected to sympathetic personal-social evaluation; a magistrate's momentary dyspepsia sends one vagrant to a house of correction and another back to the street; old and new theories of rehabilitation compete for administrative support. Whether or not these diverse and often incompatible elements will eventually be replaced by a coherent configuration based on scientific principles, the fact remains that thrusting into the present amalgam a device far more rational (in the sense of being empirically based) than the enterprise it would purportedly assist may invite some entirely unanticipated kinds of trouble. An interesting aspect of parole prediction is that it can be developed quite independently of correctional standards, since neither its logic nor its methods arise from correctional theory any more than do those, say, of mathematics. The intellectual fascination of prediction, with its elegant models, its amenability to quantification, and its limitless practical possibilities, does not in itself qualify it as a friend of good correction. Its potentials for blocking the further improvement of parole, reducing parole to a technical level, increasing the timorousness of parole boards, and obscuring the need for individual treatment may, in fact, result in its becoming good parole's worst enemy. 